\title{
ELETROFORESE DE PROTEÍNAS E ISOENZIMAS EM SEMENTES DE Copaifera langsdorffii Desf. (LEGUMINOSAE CAESALPINIOIDEAE) ENVELHECIDAS ARTIFICIALMENTE ${ }^{1}$
}

Dulcinéia de Carvalho², Robério Anastácio Ferreira ${ }^{3}$, Luciana Magda de Oliveira ${ }^{4}$, Alessandro Fabiano de Oliveira $^{5}$ e Rinã Celeste Rodrigues Gemaque ${ }^{5}$

\begin{abstract}
RESUMO - A eletroforese vem sendo utilizada com a finalidade de auxiliar a avaliação da qualidade fisiológica de sementes de espécies florestais, uma vez que respostas mais rápidas podem ser obtidas usando-se marcadores isoenzimáticos. Sementes de copaíba (Copaifera langsdorffii) foram submetidas a diferentes tempos de envelhecimento artificial $\left(0,24,48,72\right.$ e 96 horas), em germinador ( $42{ }^{\circ} \mathrm{C}$ e $100 \%$ de UR), tendo como objetivo avaliar as possíveis mudanças nos padrões eletroforéticos de proteínas e isoenzimas, decorrentes do envelhecimento artificial. O envelhecimento artificial ocasionou redução na germinação e vigor de sementes de C. langsdorffii, sendo o vigor afetado mais rapidamente. Em relação aos padrões eletroforéticos, não houve diferença significativa no conteúdo de proteínas solúveis e de armazenamento, mas, nas enzimas esterase e peroxidase, verificouse redução na atividade destas, à medida que as sementes foram envelhecidas.
\end{abstract}

Palavras-chave: Germinação e vigor de sementes, eletroforese e espécie florestal.

\section{PROTEINS AND ISOZYMES ELECTROFORESIS IN SEEDS OF Copaifera langsdorffii Desf. (LEGUMINOSAE CAESALPINIOIDEAE) ARTIFICIALLY AGED}

\begin{abstract}
Electrophoresis has been used to aid the evaluation of physiological seed quality of forest species, as isozymes provide fast responses. Seeds of copaiba (Copaifera langsdorffii) were artificially aged for 0 , 24, 48, 72 and 96 hours, in a germination chamber ( $42^{\circ} \mathrm{C}$ and $100 \%$ UR). The objective of this research was to evaluate possible changes in the electrophoretic patterns of proteins and isozymes during the artificial aging. The artificial aging reduced the germination and vigor of C. langsdorffii seeds, but vigor was affected faster than germination. The electrophoretic patterns showed no difference in the content of soluble and storage proteins, but for esterase and peroxidase isozymes there was reduction in the activity with aging.
\end{abstract}

Keywords: Seed germination, artificial aging, electrophoresis and Copaifera langsdorffii.

\footnotetext{
${ }^{1}$ Recebido em $1^{\circ} .09 .2003$ e aceito para publicação em 10.11.2005.

${ }^{2}$ Departamento de Ciências Florestais da UFLA. Cx.P. 37, 37200-000 Lavras-MG. E-mail: <dulce@rumba.ufla.br>.

${ }^{3}$ Departamento de Engenharia Agronômica - DEA/UFS. Av. Marechal Rondon, S/N - Cidade Universitária. Prof. José Aloísio de Campos - Jardim Rosa Elze, São Cristovão-SE - 49100-000. E-mail: <raf@ufs.br>.

${ }^{4}$ Programa de Pós-Graduação em Agricultura - DAG/UFLA. Cx. P. 37, 37200-000 Lavras-MG. E-mail: <lu.magda@ig.com.br>.

${ }^{5}$ Programa de Pós-Graduação em Engenharia Florestal da UFLA. Cx. P.37, 37200-000 Lavras-MG.
} 


\section{INTRODUÇÃO}

A eletroforese vem sendo utilizada no estudo de proteínas e isoenzimas com relação não apenas às mudanças na qualidade fisiológica de sementes, mas também nas regulações gênica, bioquímica e ontogênica, entre outros (ISTA, 1992). Na tecnologia de sementes, uma das maiores dificuldades para avaliar a qualidade de sementes refere-se ao tempo para execução dos testes. Desse modo, novos testes devem ser realizados para obter resultados efetivos e mais rápidos, na tentativa de predizer a qualidade dos lotes que chegam ao laboratório.

Dentre os testes empregados com tal objetivo, o envelhecimento artificial, utilizando-se alta temperatura e alta umidade relativa, faz que as sementes passem por rápida e intensa deterioração, propiciando uma avaliação mais rapidamente de sua qualidade fisiológica, em relação a outros testes (MARCOS FILHO, 1992). Nesse sentido, o conhecimento do processo de deterioração, envolvendo reações em diferentes intensidades, é fundamental na busca de marcadores que revelem, com a máxima segurança, a condição do material examinado (VIEIRA, 1996).

Durante o período de armazenamento de sementes, é necessário manter condições adequadas de temperatura e umidade, na tentativa de preservar a qualidade destas. Muitas vezes, a falta de conhecimento das condições ideais de armazenamento torna difícil a manutenção da qualidade fisiológica das sementes, pois o envelhecimento é um processo natural. Um dos primeiros eventos da deterioração de sementes é a perda da integridade das suas membranas, o que afeta a permeabilidade, a compartimentalização e a separação dos sistemas metabólicos (BASU, 1995). De acordo com esse autor, muitas enzimas estão associadas aos sistemas de membranas, e qualquer mudança nessa integridade teria conseqüências fisiológicas e bioquímicas. Além da perda da integridade das membranas, observam-se redução na produção de ATP e na síntese de proteínas e ácidos nucléicos e degeneração cromossômica (BEWLEY e BLACK, 1994).

No caso de sementes, os marcadores isoenzimáticos têm sido empregados em estudos de viabilidade, pois são eficientes para se conhecerem eventos importantes do tempo de vida, das mudanças deteriorativas e da morte da semente (BASU, 1995).
Copaifera langsdorffii Desf., conhecida como copaíba e óleo-copaíba, ocorre nos Estados de MG, GO, MS, SP e PR, sendo característica da floresta latifoliada. A espécie fornece óleo com propriedades medicinais, e a madeira pode ser empregada na construção civil e confecção de móveis (LORENZI, 1992). De acordo com esse autor, presta-se ainda para a arborização urbana e recuperação de áreas degradadas. As sementes maduras são exalbuminosas, ricas em amilóide, proteínas e óleos em abundância, armazenados nos cotilédones (CRESTANAe BELTRATI, 1988). De acordo com Carvalho (1994), a espécie apresenta dormência ocasional, promovida pela presença de cumarina no tegumento

Do ponto de vista da tecnologia de sementes, a maior dificuldade encontrada na espécie é manter as sementes viáveis durante o armazenamento, uma vez que estas apresentam longevidade variando de dois meses (GONZÁLES e TORRES, 2003), de um a dois anos (DAVIDE et al., 1995) até quatro anos (CARVALHO, 1994). O objetivo deste trabalho foi avaliar as alterações nos padrões eletroforéticos de proteínas e isoenzimas em sementes de copaíba (Copaifera langsdorffii) submetidas a diferentes tempos de envelhecimento artificial, de modo a auxiliar a predição da sua qualidade para fins de armazenamento.

\section{MATERIAL E MÉTODOS}

O trabalho foi realizado no Laboratório de Sementes Florestais (LSF) e Laboratório de Melhoramento do Departamento de Ciências Florestais (DCF), da Universidade Federal de Lavras (UFLA). Foram colhidos frutos de seis matrizes, distantes no mínimo 100 m entre si, na região de Lavras, MG. A cidade localiza-se no sul do estado, $21^{\circ} 14^{\prime} \mathrm{S}$ e $45^{\circ} 0^{\prime}$ ' W, a $900 \mathrm{~m}$ de altitude. Apresenta clima do tipo Cwb (clima temperado úmido com inverno seco), segundo a classificação de Köppen. A temperatura média anual é de $19,4{ }^{\circ} \mathrm{C}$ e a precipitação média anual, de 1.529,7 mm (BRASIL, 1992a).

Os frutos foram colhidos diretamente das árvoresmatriz, utilizando-se podão, quando apresentavam sinais de abertura espontânea. A secagem foi realizada em pleno sol até a completa abertura, quando as sementes foram removidas, como sugerido por Davide et al. (1995). Após o beneficiamento das sementes, o lote foi homogeneizado para retirada das amostras, que foram submetidas ao envelhecimento artificial. 


\subsection{Envelhecimento artificial}

Para promover o envelhecimento artificial das sementes foi utilizado o germinador Mangelsdorf Elo's, a $42{ }^{\circ} \mathrm{C}$ e $100 \%$ de umidade relativa. As sementes foram colocadas em gerbox contendo $40 \mathrm{~mL}$ de água destilada, as quais foram mantidas separadas da água com tela de náilon (5 mm). Os tempos de envelhecimento corresponderam a 0, 24, 48, 72 e 96 horas. Em cada tempo foram utilizadas 130 sementes, das quais 100 foram empregadas para a condução dos testes de germinação e 30 para a determinação da umidade e análises dos perfis eletroforéticos de proteínas e isoenzimas.

\subsection{Avaliação da qualidade fisiológica das sementes}

Para avaliação da qualidade fisiológica das sementes, foram realizados testes de germinação, conduzidos em germinador Mangelsdorf Elo’s, em temperatura constante de $25^{\circ} \mathrm{C}$, sob luz contínua, durante o período de 30 dias. As sementes foram semeadas em bandejas de polietileno, contendo como substrato areia peneirada, lavada e autoclavada $\left(120^{\circ} \mathrm{C}\right.$ por 20 minutos). Para a instalação, as sementes foram desinfestadas com hipoclorito de sódio $2 \%$ durante dois minutos, enxaguadas em água destilada e semeadas sobre o substrato. Foram utilizadas quatro repetições de 25 sementes para cada tempo de envelhecimento.

As avaliações foram realizadas a cada dois dias, considerando-se como germinadas quando apresentaram a emissão da radícula (critério botânico) e plântulas normais (tecnologia de sementes). A umidade inicial das sementes e após cada tempo de envelhecimento foi determinada em estufa a $103^{\circ} \mathrm{C}$, por 17 horas, utilizandose quatro repetições de $1 \mathrm{~g}$ de sementes, as quais foram quebradas com o auxílio de faca e martelo. O teor de água foi calculado de acordo com as Regras para Análise de Sementes (BRASIL, 1992b).

Durante a realização dos testes de germinação foi avaliado o vigor das sementes, através do índice de velocidade de germinação (IVG), proposto por Maguire (1962), considerando-se as plântulas normais.

Os testes foram realizados empregando-se o delineamento inteiramente casualizado (DIC). As análises estatísticas foram realizadas no programa SANEST, sendo os dados transformados em arco-seno raiz quadrada de $\mathrm{x} / 100$ e as médias, comparadas através do teste de Tukey a 5\% de significância.

\subsection{Análise dos perfis eletroforéticos de proteínas e isoenzimas}

Para a determinação dos perfis eletroforéticos, após cada tempo de envelhecimento as sementes foram moídas na presença de PVP-40 (polivinilpirrolidona) e liofilizadas.

Para a extração de proteínas solúveis, amostras de $100 \mathrm{mg}$ de sementes moídas, de cada tempo de envelhecimento, foram maceradas em $\mathrm{N}_{2}$ líquido, com o auxílio de uma haste plástica, sendo as proteínas extraídas em 3 mL de tampão Hepes 100 mM. Após a maceração, as amostras foram incubadas no gelo por 20 minutos e centrifugadas por 10 minutos a $4{ }^{\circ} \mathrm{C}$ e $14.000 \mathrm{rpm}$, sendo acrescentados $200 \mu \mathrm{L}$ do tampão Laemmli 2x. Para a corrida eletroforética, de cada amostra foram utilizados $60 \mu \mathrm{L}$ de extrato e adicionados $20 \mu \mathrm{L}$ do tampão da amostra (LAEMMLI, 1970), fervidos durante cinco minutos e aplicados no gel.

Para a extração das proteínas de armazenamento foi utilizado o "pellet” recolhido da extração de proteínas solúveis, adicionando-se às amostras $200 \mu \mathrm{L}$ do tampão Laemmli e fervendo durante cinco minutos. Os macerados foram centrifugados durante 10 minutos a $4{ }^{\circ} \mathrm{C}$ e 14.000 rpm e o sobrenadante, recolhido. Para a corrida eletroforética, em $60 \mu \mathrm{L}$ do sobrenadante foram adicionados $20 \mu \mathrm{L}$ de tampão de Laemmli $1 \mathrm{x}$ das amostras, que foram fervidas durante cinco minutos e aplicadas no gel.

Para as análises de proteínas solúveis e de armazenamento, a corrida eletroforética foi realizada utilizando-se gel de poliacrilamida, em sistema descontínuo SDS-PAGE, sendo empregados gel separador $12 \%$ e gel concentrador $4 \%$. A coloração dos géis foi realizada com azul-de-coomassie.

Para a extração das enzimas foram utilizados 150 mg de sementes moídas, sendo as amostras maceradas com 3 mL de tampão de extração (Tris-HCl 0,2M, pH 8,0; EDTA 1mM; PVP0,4\%; PEG 0,4\% eb-Mercaptoetanol $0,2 \%$ ), em nitrogênio líquido; foi utilizado o vórtex, sendo as sementes centrifugadas por 20 minutos a $4{ }^{\circ} \mathrm{C}$ e $14.000 \mathrm{rpm}$. O “pellet” foi descartado e o sobrenadante, empregado na eletroforese. A corrida eletroforética foi realizada utilizando-se o sistema PAGE, em gel de poliacrilamida, sendo o separador 7,5\% e o concentrador $4 \%$. Para análise do perfil isoenzimático, foram utilizadas as enzimas esterase (EST-EC 3.1.1.1) e peroxidase (PO-EC 1.11.1.7), de acordo com a metodologia descrita por Alfenas (1998).

R. Árvore, Viçosa-MG, v.30, n.1, p.19-24, 2006 


\section{RESULTADOS E DISCUSSÃO}

\subsection{Germinação e vigor das sementes}

O envelhecimento artificial empregado nas sementes de $C$. langsdorffii interferiu diretamente na sua qualidade fisiológica (Tabela 1). Até 24 horas de envelhecimento, não se observou diferença em relação ao controle (0 hora). No entanto, a partir desse período, pode-se constatar redução significativa no porcentual de emissão de radícula e plântulas normais e no IVG. De acordo com Bewley e Black (1994), Basu (1995) e Desai et al. (1997), isso pode ser explicado pelas mudanças promovidas no sistema de membranas e pela rápida degradação das substâncias de reserva, promovidas pela intensa atividade de enzimas hidrolíticas, quando as sementes são submetidas a condições adversas de temperatura e umidade. Durante o processo de deterioração de sementes, segundo Desai et al. (1997), verifica-se que o vigor é afetado mais rapidamente do que a viabilidade, fato comprovado também neste trabalho.

No decorrer do experimento, nos testes de germinação foi observado incidência dos fungos Aspergillus sp., Penicillium sp. e Cladosporium sp., sendo maior a partir de 48 horas de envelhecimento artificial. A identificação foi realizada na Clínica Fitopatológica da UFLA. Deve-se considerar também que a presença dos fungos citados podem ter contribuído para a redução da germinação e do vigor de sementes, após o envelhecimento.

Tabela 1 - Umidade, germinação e vigor de sementes de copaíba (Copaifera langsdorffii) submetidas a diferentes tempos de envelhecimento artificial (EA). Valores médios de teor de água (TA), emissão de radícula (ER), plântulas normais (PN) e índice de velocidade de germinação (IVG)

Table 1 - Moisture content, germination and vigor of seeds of copaíba (Copaifera langsdorffii) at different times of artificial aging (EA). Moisture content (TA), radicle emergence (ER), normal seedlings $(P N)$ and germination velocity index (IVG)

\begin{tabular}{ccccc}
\hline EA (h) & TA (\%) & ER (\%) & PN (\%) & IVG \\
\hline 0 & $14,4 \mathrm{a}$ & $96 \mathrm{a}$ & $89 \mathrm{a}$ & $1.32 \mathrm{a}$ \\
24 & $21,2 \mathrm{~b}$ & $95 \mathrm{a}$ & $90 \mathrm{a}$ & $1.17 \mathrm{~b}$ \\
48 & $34,2 \mathrm{c}$ & $82 \mathrm{~b}$ & $77 \mathrm{ab}$ & $0.89 \mathrm{c}$ \\
72 & $34,6 \mathrm{c}$ & $84 \mathrm{~b}$ & $69 \mathrm{~b}$ & $0.99 \mathrm{c}$ \\
96 & $43,4 \mathrm{~d}$ & $26 \mathrm{c}$ & $19 \mathrm{c}$ & $0.30 \mathrm{~d}$ \\
\hline
\end{tabular}

* Médias nas colunas, seguidas da mesma letra, não diferem entre si, pelo teste de Tukey a $5 \%$.

\subsection{Análise de proteínas e isoenzimas}

Os zimogramas dos perfis eletroforéticos de proteínas indicam que os tempos de envelhecimento artificial utilizados não promoveram alterações nos padrões de proteínas solúveis e de armazenamento (Figura 1), não sendo recomendada a sua avaliação para monitoramento da qualidade de sementes durante o armazenamento de sementes de C. langsdorffii. Em todos os tempos de envelhecimento, verificou-se a presença de três bandas mais intensas, com peso molecular de 16,4; 34,1; e 48,2 kDa. Destas, a banda de 34,1 kDa corresponde à classe das leguminas, como mencionado por Luthe (1992). Segundo esse autor, as leguminas presentes também em Magnolia grandiflora, uma espécie primitiva, apresentam peso molecular variando de 30 a $40 \mathrm{kD}$. No entanto, não foram observadas bandas correspondentes às proteínas da classe das vicilinas, que têm peso molecular variando de 50 a $75 \mathrm{kDa}$ (DERBYSHIRE et al., 1976).

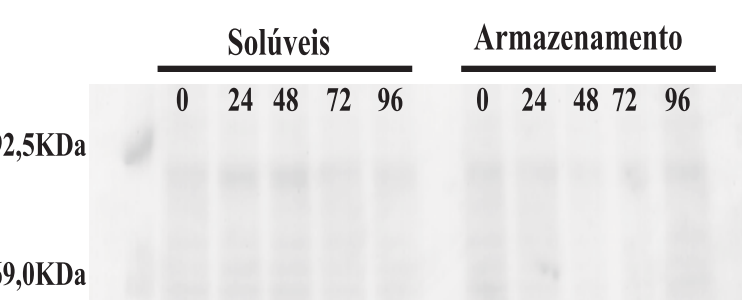

$46,0 \mathrm{KDa}$

30,0KDa

14,5KDa

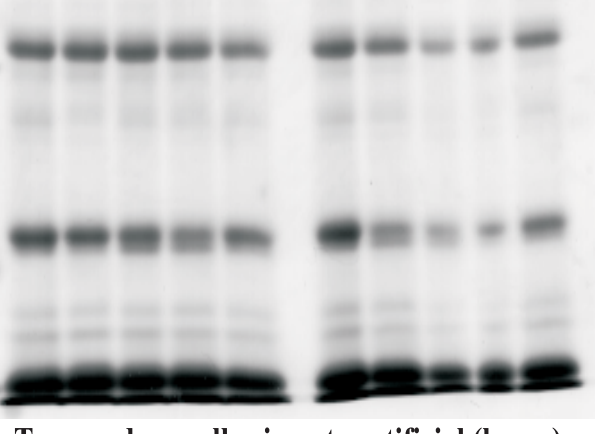

Tempos de envelhecimento artificial (horas)

Figura 1 - Padrão eletroforético de proteínas solúveis e de armazenamento utilizando-se tampão Tris-HCl, em sementes de copaíba (Copaifera langsdorffii) submetidas ao envelhecimento artificial.

Figure 1-Electroforetic pattern of soluble and storage proteins using Tris-HCl buffer, in artifically aged seeds of copaiba (Copaifera langsdorffii). 
O zimograma do perfil eletroforético da isoenzima esterase (Figura 2), que está relacionada à hidrólise de ésteres, mostra que houve variação na atividade desta, em razão do tempo de envelhecimento. Podese observar que, nos tempos de 0 e 24 horas, as bandas foram mais intensas, diminuindo a seguir. Conseqüentemente, a redução da sua atividade impede que os fosfolipídios das membranas permaneçam eficientemente protegidos. Desse modo, com a desestruturação destes, verificou-se que o sistema de membranas das organelas entram em declínio, tornandose mais suscetíveis aos efeitos deletérios do $\mathrm{O}_{2}$ e permitindo maior produção de lixiviados, à medida que as sementes são envelhecidas (BEWLEY e BLACK, 1994).

Para a peroxidase, cuja perda de atividade pode tornar a semente mais sensível aos efeitos do $\mathrm{O}_{2}$ e radicais livres, o zimograma indica que houve mudança na sua atividade, em função de envelhecimento artificial (Figura 3). As bandas apresentaram-se mais intensas nos tempos de 0 e 24 horas e diminuíram a partir de 48 horas, indicando uma provável redução da sua atividade nas sementes em estádio de deterioração mais avançado. Esses resultados foram semelhantes aos obtidos por Brandão Júnior (1996) e Vieira (1996) com sementes de milho (Zea mays) e algodão (Gossypium hirsutum), respectivamente. Para Vieira (1996), a perda completa da atividade da peroxidase, durante o envelhecimento, pode esclarecer parcialmente o acúmulo de peróxidos em sementes envelhecidas.

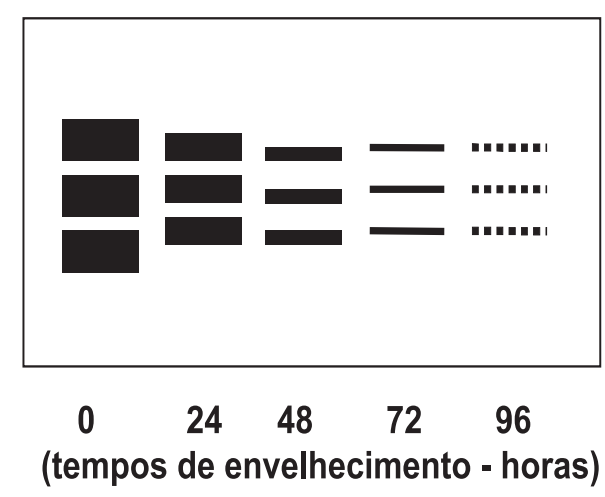

Figura 2 - Padrão eletroforético da esterase em sementes de copaíba (Copaifera langsdorffii) submetidas ao envelhecimento artificial.

Figure 2 - Electroforetic pattern of esterase in artificially aged seeds of copaiba (Copaifera langsdorffii).

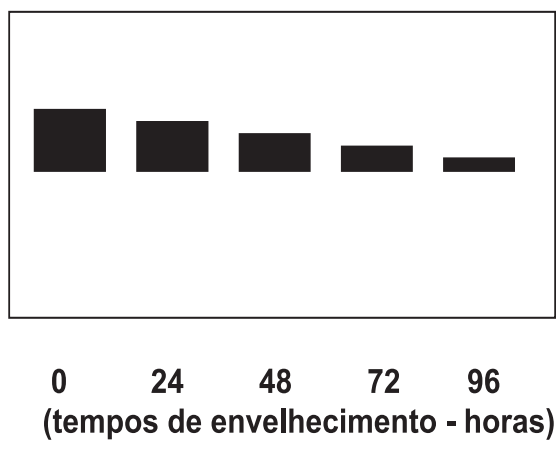

Figura 3 - Padrão eletroforético da peroxidase em sementes de copaíba (Copaifera langsdorffii) submetidas ao envelhecimento artificial.

Figure 3-Electroforetic pattern of peroxidase in artificially aged seeds of copaiba (Copaifera langsdorffii).

De acordo com Bewley e Black (1994), a redução da atividade dessa enzima proporciona maior exposição dos sistemas de membranas aos efeitos do $\mathrm{O}_{2}$. Com isso, em decorrência do nível de danos das membranas, o $\mathrm{O}_{2}$ atua de forma mais intensa, promovendo oxidação dos compostos. De forma análoga, tais efeitos foram comprovados neste trabalho.

Segundo Desai et al. (1997), o declínio na atividade da peroxidase, como pôde ser observado em $C$. langsdorffii, assim como de enzimas como citocromo oxidase, malato e álcool desidrogenase, desidrogenase succínica e glutâmica e catalase, em sementes nãoviáveis, pode contribuir significativamente para a redução da atividade respiratória. De modo contrário, a produção de isoenzimas e enzimas respiratórias é um indicador de que o embrião está viável. Nesse sentido, a ausência de mecanismos que tornem essas sementes capazes de corrigir tais deficiências, durante o desenvolvimento ou armazenamento, pode estar associada à perda da viabilidade da semente.

\section{CONCLUSÕES}

a) O envelhecimento acelerado ocasionou redução na germinação e vigor de sementes de C. langsdorffii, sendo o vigor afetado mais rapidamente do que a germinação.

b) Não foram detectadas mudanças nos padrões eletroforéticos de proteínas solúveis e de armazenamento em função dos diferentes tempos de envelhecimento artificial.

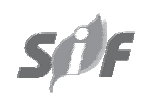

R. Árvore, Viçosa-MG, v.30, n.1, p.19-24, 2006 
c) Nos sistemas isoenzimáticos esterase e peroxidase, o tempo de envelhecimento artificial influenciou, de forma significativa, a atuação dessas, sendo observado redução da sua atividade à medida que as sementes foram envelhecidas. Portanto, podem ser empregadas para avaliação da qualidade fisiológica de sementes durante o armazenamento, uma vez que a redução da atividade destas indicou perda da capacidade germinativa.

\section{REFERÊNCIAS BIBLIOGRÁFICAS}

ALFENAS, A.C. et al. Eletroforese de proteínas $e$ isoenzimas de fungos e essências florestais. Viçosa, MG:

Universidade Federal Viçosa, 1991. 242p.

BASU, R.N. Seed viability. In: BASRA, A.S. Seed quality: basic mechanisms and agricultural implications. New York: The Haworth Press, 1995. p.1-42.

BEWLEY, J.D.; BLACK, M. Seeds: physiology of development and germination. 2. ed. New York: Plenum Press, 1994. 455p.

BRADFORD, M.M. A rapid and sensitive method for the quantification of microgram quantities of proteins utilizing the principle of protein-dye binding. Analytical Biochemistry, v. 72, p. 248-254, 1976.

BRANDÃO JUNIOR, D.S. Eletroforese de proteína e isoenzima na avaliação da qualidade de sementes de milho. 1996, 110 f. Dissertação (Mestrado em Agronomia) Universidade Federal de Lavras, Lavras, 1996.

BRASIL. Ministério da Agricultura e Reforma Agrária. Normais climatológicas de 19611990. Brasília: Secretaria Nacional de Irrigação/ Departamento Nacional de Meteorologia, 1992a. 84p.

BRASIL. Ministério da Agricultura e Reforma Agrária. Regras para análise de sementes. Brasília: SNDA/DNDV/CLAV, 1992b. 362p.

CARVALHO, P.E.R. Espécies florestais brasileiras: recomendações silviculturais potencialidades e uso da madeira. Brasília: EMBRAPA-CNPF/SPI, 1994. 640p.

CRESTANA, C.M.; BELTRATI, C.M. Morfologia e anatomia de sementes de Copaifera langsdorffii Desf. (Leguminosae - Caesalpinioideae).

Naturalia, v.13, p.45-54, 1988.
DAVIDE, A.C.; FARIA, J.M.R.; BOTELHO, S.A. Propagação de espécies florestais. Belo Horizonte: CEMIG/UFLA/FAEPE, 1995. 45p.

DERBYSHIRE, E.; WRIGHT, D.J.; BOULTER, D. Legumin and vicilin, storage proteins of legume seeds. Phytochemistry, v.15, p.3-24, 1976.

DESAI, B.B.; KOTECHA, P.M.; SALUNKE, D.K. Seeds handbook: biology, production, processing and storage. New York: Marcel Dekker, 1997. 627p.

GONZÁLES, S.; TORRES, R.A.A. Coleta de sementes. In: SALOMÃO, A.N. et al.

Germinação de sementes e produção de mudas de plantas do cerrado. Brasília: Rede de Sementes do Cerrado, 2003. p.11-74.

INTERNATIONAL SEED TESTING ASSOCIATION. ISTA. Handbook of variety testing: electrophoresis testing. Zürich: ISTA, 1992.

LAEMMLI, U.K. Cleavage of structural proteins during the assembly of the head of bacteriophage T4. Nature, v.277, p.680-685, 1970.

LORENZI, H. Árvores brasileiras: manual de identificação e cultivo de plantas arbóreas nativas do Brasil. Nova Odessa: Plantarum, 1992. 352p.

LUTHE, D.S. Electroforetic analysis of seed proteins in the dicotyledoneae. Plant Molecular Biology Reporter, v.10, n.3, p.254-262, 1992.

MAGUIRE, J. D. Speed of germination-aid in selection and evaluation for seedling emergence and vigor. Crop Science, v. 2, p. 176-177, 1962.

MARCOS FILHO, J. Teste de envelhecimento acelerado. In: VIEIRA, R.D.; SADER, R.; CARVALHO, N.M. Curso sobre testes de vigor de sementes. Jaboticabal: UNESP, 1992. p.45-57.

VIEIRA, M. G.G.C. Utilização de marcadores moleculares no monitoramento da qualidade sanitária a nível de deterioração de sementes de algodoeiro (Gossypium hirsutum L.). 1996.

114f. Tese (Doutorado em Fitotecnia) Univesidade Federal de Lavras, Lavras, 1996. 